\title{
POS-GRADUAÇÃO NA MODALDIADE DE EDUCAÇÃO A DISTÂNCIA
}

\author{
FIGUEIREDO, Márcia Aparecida ${ }^{1}$ \\ BASSOLI, Dyjalma Antonio²
}

\begin{abstract}
Resumo
Este artigo discute as características dos cursos de Pós-graduação a distância e os conceitos apresentados pelos autores no decorrer da evolução dessa modalidade de ensino. Enquadrada no pensamento estratégico, a educação é um processo histórico que retrata e reproduz a sociedade, mas também projeta a sociedade que se quer. Nessa perspectiva, tem o desafio de responder às demandas que os contextos the colocam. Desafios esses relacionados à fragmentação do conhecimento, que poderão ser modificados por uma prática reflexiva e propiciadora de crescimento. Os cursos de Pós-graduação a distância é uma modalidade que pode ser aplicada em diversas concepções e metodologias de Educação. Assim, a educação deixa de ser concebida como transferência de informações e passa a ser norteada pela contextualização de conhecimentos úteis ao aluno. Um saber que se reexamina, que revê sua própria identidade, que se reprograma e se reconstrói. Ao mesmo tempo, os cursos de Pós-graduação a distância também vem se requalificando, fixando novas fronteiras.
\end{abstract}

Palavras-chave: Pós-graduação a distância, Inovação tecnológica, Sociedade do conhecimento

\section{Introdução}

$\mathrm{Na}$ sociedade atual, onde o conhecimento e as inovações tecnológicas estão, cada vez mais, ao alcance dos alunos fora do espaço escolar, a função social das IES e o papel do educador adquirem outra dimensão, diferente daquela que, em tempos anteriores, era por muitos apregoada, ou seja, agente principal de difusão do conhecimento e da informação.

\section{A trajetória histórica da EaD}

\footnotetext{
${ }^{1}$ Centro Universitário Barão de Mauá: marciaead@baraodemaua.br

2 Centro Universitário Barão de Mauá: dyjalma.bassoli@baraodemaua.br
} 
A trajetória da $\mathrm{EaD}$ no Brasil se desenvolve em meio às políticas e dinâmicas adotadas do país, no contexto da reforma do Estado e da reforma do sistema educativo, em articulação com os processos transnacionais, destacando-se as recomendações dos organismos multilaterais (UNESCO, BM, entre outros) que a recomendam como modalidade educativa a ser expandida e institucionalizada (DOURADO, 2008; SANTOS, 2010,)

Segundo SANTOS (2010), "No Brasil, a história da EaD data pelo menos de 1904, quando foram instaladas as chamadas escolas internacionais, instituições privadas que ofereciam cursos por correspondência. No entanto, segundo Alves (2001), em 1891, os jornais já traziam anúncios de ensino por correspondência. (...) O marco da utilização da EaD no país ocorreu com a utilização da radiodifusão com fins educativos em 1936, com a instalação por Edgard Roquete-Pinto da RádioEscola Municipal. (...) Já em 1939, foi criado o Instituto Universal Brasileiro, que oferecia cursos técnico-profissionais por correspondência considerados os mais antigos e conhecidos cursos a distância no país. Desde então, há registros de experiências periódicas, algumas mais abrangentes, outras mais localizadas, algumas desenvolvidas e outras que ficaram só no projeto (...)”.

\title{
Pós- Graduação - Ambientes de aprendizagem e formação
}

Um dos grandes desafios do século é a qualidade da educação, assim como a formação e a valorização humana, apontada como solução para o desenvolvimento das nações.

\begin{abstract}
as instituições educativas têm por tarefa preparar os jovens para o mundo do trabalho, que, entre outras coisas, exige deles novas competências: criar, pensar, propor soluções, conviver em equipe - competências essas compatíveis com as novas configurações do processo produtivo. Essas transformações estão modificando significativamente a identidade do trabalhador, que passou, da noite para o dia, a ser valorizado como alguém que deve pensar e propor, embora com a finalidade de gerar maior produtividade, que gere maior lucro. (PIMENTA, Selma Garrido, 2002,. p. 100-101).
\end{abstract}

A fim de potencializar a capacidade de aprendizagem de novos saberes, foram criados cursos de Pós-graduação em algumas universidades brasileiras. Em primeiro lugar, impõe-se distinguir os conceitos de Pós-graduação Lato Sensu e 
Stricto Sensu. No primeiro sentido, tem-se, como seguimento, a graduação, cursos de especialização que tem por objetivo técnico profissional em abranger o campo específico do saber ou da profissão. Prevê cursos destinados ao ramo profissional ou científico. Enquanto o segundo, em sentido restrito, define o sistema de cursos que se superpõe à graduação com objetivos mais amplos e aprofundados de formação científica ou cultural. Com o crescimento de oferta espontânea, o governo passou a criar instrumentos de Avaliação de qualidade. Começa, então, a haver um processo de consolidação entre as instituições particulares. Muitas delas reestruturaram modelos curriculares e programáticos superados, diante das exigências de um mundo competitivo.

De fato, as transformações atingem as instituições escolares de modo contundente. Seus princípios são questionados, currículos são revistos, avaliações são implementadas, tendentes a dotar qualidade ao ensino/aprendizagem. Padrões que normalizem a escolarização são admitidos. Há também incentivo para novas experiências educativas pautadas, geralmente, por políticas que, ao financiarem determinados programas, tentam implicar as escolas em outras dinâmicas de ensino/ aprendizagem. (ALONSO, Katia Morosov, 2008)

Nas propostas de transformações, destaca-se, numa esfera atual e global, o uso mais intenso de computadores/TICs. As pessoas cresceram culturalmente e profissionalmente. Diante dessa realidade, o papel das IES é de transformar o processo de ensino-aprendizagem. Pretende-se que a incorporação das TICs no ensino de Pós-graduação seja elemento catalizador de mudanças significativas na aprendizagem dos alunos.

Na modalidade de Educação a Distância, são 174 Instituições de Ensino Superior que oferecem 3.293 Cursos de Pós-graduação; ativos 3.203, desativados 90; abaixo a Tabela 1, por distribuição de Unidade da Federação (UF).

Tabela 1: Distribuição dos Cursos de Pós-graduação Ativos e Desativados por Unidade da Federação (UF),

\begin{tabular}{lllll}
\hline \multirow{2}{*}{ UF } & \multicolumn{2}{l}{ Ativo } & \multicolumn{2}{c}{ Desativado } \\
\cline { 2 - 5 } & $\boldsymbol{f}$ & $\%$ & $\boldsymbol{f}$ & $\%$ \\
\hline AL & 2 & $0,1 \%$ & 0 & $0,0 \%$ \\
AM & 21 & $0,7 \%$ & 0 & $0,0 \%$ \\
AP & 4 & $0,1 \%$ & 0 & $0,0 \%$ \\
BA & 14 & $0,4 \%$ & 1 & $1,1 \%$
\end{tabular}




\begin{tabular}{cllll} 
CE & 179 & $5,6 \%$ & 0 & $0,0 \%$ \\
DF & 43 & $1,3 \%$ & 0 & $0,0 \%$ \\
ES & 44 & $1,4 \%$ & 0 & $0,0 \%$ \\
GO & 11 & $0,3 \%$ & 0 & $0,0 \%$ \\
MA & 11 & $0,3 \%$ & 0 & $0,0 \%$ \\
MG & 245 & $7,6 \%$ & 9 & $10,0 \%$ \\
MS & 103 & $3,2 \%$ & 0 & $0,0 \%$ \\
MT & 9 & $0,3 \%$ & 0 & $0,0 \%$ \\
PA & 8 & $0,2 \%$ & 0 & $0,0 \%$ \\
PB & 15 & $0,5 \%$ & 0 & $0,0 \%$ \\
PE & 51 & $1,6 \%$ & 0 & $0,0 \%$ \\
PI & 11 & $0,3 \%$ & 0 & $0,0 \%$ \\
PR & 365 & $11,4 \%$ & 49 & $54,4 \%$ \\
RJ & 850 & $26,5 \%$ & 0 & $0,0 \%$ \\
RN & 14 & $0,4 \%$ & 0 & $0,0 \%$ \\
RO & 5 & $0,2 \%$ & 0 & $0,0 \%$ \\
RR & 6 & $0,2 \%$ & 0 & $0,0 \%$ \\
RS & 109 & $3,4 \%$ & 7 & $7,8 \%$ \\
SC & 220 & $6,9 \%$ & 4 & $4,4 \%$ \\
SE & 3 & $0,1 \%$ & 0 & $0,0 \%$ \\
SP & 850 & $26,5 \%$ & 20 & $22,2 \%$ \\
TO & 10 & $0,3 \%$ & 0 & $0,0 \%$ \\
\hline Total & $\mathbf{3 2 0 3}$ & $\mathbf{1 0 0 , 0} \%$ & $\mathbf{9 0}$ & $\mathbf{1 0 0 , 0} \%$ \\
\hline
\end{tabular}

Fonte: Ministério da Educação - Sistema e-MEC

Relatório Processado: 20/04/2015

Como é possível observar na Tabela 1 e Figura 1, as Unidades da Federação que possuem maior frequência de cursos de Pós-graduação são: São Paulo e Rio de Janeiro, cada uma com $26,5 \%$, totalizando $53 \%$ dos cursos oferecidos no Brasil.

Figura 1: Cursos de Pós-graduação por Unidade da Federação (UF). 


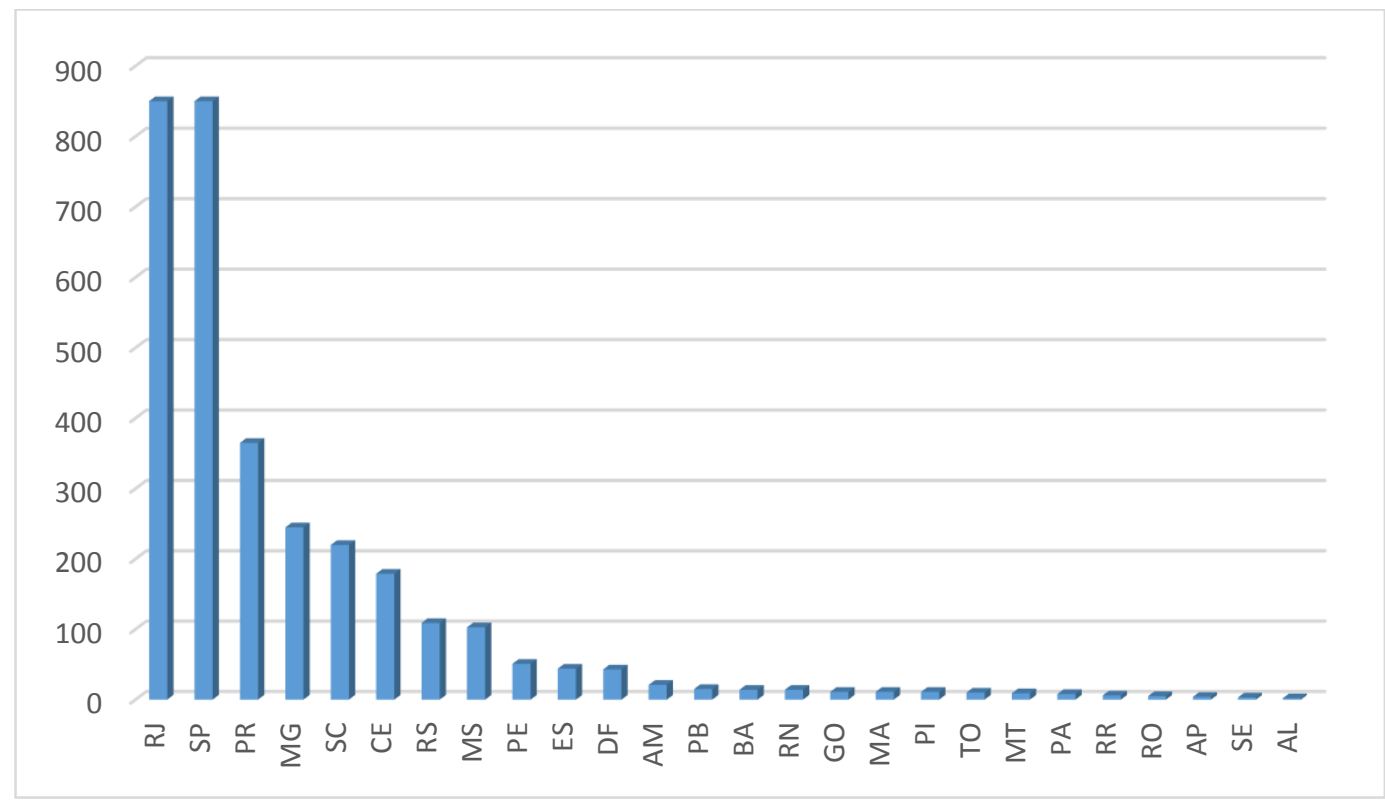

Fonte: Ministério da Educação - Sistema e-MEC

Relatório Processado: 20/04/2015

Figura 2: Mapeamento do Brasil - Cursos de Pós-graduação na modalidade de EAD.

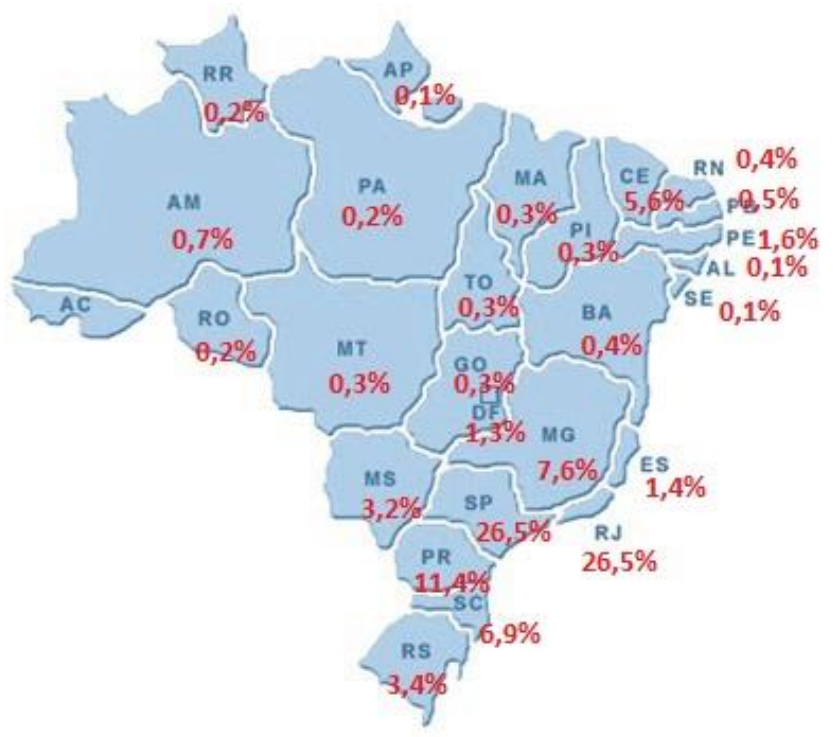

Já, de acordo com a Figura 2, a Região Sudeste possui $62,1 \%$ das Instituições de Ensino Superior com Cursos de Pós-graduação, totalizando 1989 cursos; a Região Sul com 21,7\%, com 694 cursos; A Região Nordeste 9,4\%, com 300 cursos; A Região Centro-Oeste 5,2\%, com 166 cursos; a Região Norte 1,7\%, com 54 cursos. 
Uma grande variedade de ferramentas de comunicação e de abordagens específicas para diversas situações levou à necessidade de organizar tais ferramentas em ambientes construídos especificamente para suprir as necessidades de mediação do processo educacional, ora denominados de ambientes virtuais de aprendizagem.

Para assegurar o acesso aos cursos de Pós-graduação a segmentos cada vez maiores da população, em qualquer estado ou país, sempre usando tecnologias populares, como televisão (apoiada pelo material impresso) e Internet, algumas instituições têm buscado um público crescente para o EaD.

Tabela 2: Áreas dos Cursos de Pós-graduação na modalidade EAD.

\begin{tabular}{llllll}
\hline Áreas dos Cursos de & Pós- & \multicolumn{2}{c}{ Ativo } & \multicolumn{3}{c}{ Desativado } \\
\cline { 2 - 6 } graduação em EAD & $\boldsymbol{f}$ & $\%$ & $\boldsymbol{f}$ & $\%$ \\
\hline Agricultura e veterinária & 28 & $0,9 \%$ & 2 & $2,2 \%$ \\
Ciências sociais, negócios e direito & 1276 & $39,8 \%$ & 49 & $54,4 \%$ \\
Ciências, matemática & $\mathrm{e}$ & & & \\
computação & 157 & $4,9 \%$ & 3 & $3,3 \%$ \\
Educação & 1020 & $31,8 \%$ & 24 & $26,7 \%$ \\
Engenharia, produção e construção & 83 & $2,6 \%$ & 1 & $1,1 \%$ \\
Humanidades e artes & 206 & $6,4 \%$ & 0 & $0,0 \%$ \\
Saúde e bem estar social & 397 & $12,4 \%$ & 11 & $12,2 \%$ \\
Serviços & 36 & $1,1 \%$ & 0 & $0,0 \%$ \\
\hline Total & $\mathbf{3 2 0 3}$ & $\mathbf{1 0 0 , 0 \%}$ & $\mathbf{9 0}$ & $\mathbf{1 0 0 , 0} \%$ \\
\hline
\end{tabular}

Fonte: Ministério da Educação - Sistema e-MEC

Relatório Processado: 20/04/2015

De acordo com a Tabela 2 e Figura 3, as áreas dos 3.203 cursos de Pósgraduação, a maioria dos $71,6 \%$, estão nas áreas de: Ciências sociais, negócios e direito $(39,8 \%)$ e Educação (31,8\%). As informações foram analisadas do sistema e-MEC, onde todas as IES tiveram que registrar seus cursos de Pós-graduação Lato sensu, como especializações e MBAs (Master Business in Administration) no $2^{\circ}$ semestre de 2014.

Figura 3: Áreas dos Cursos de Pós-graduação ativo 


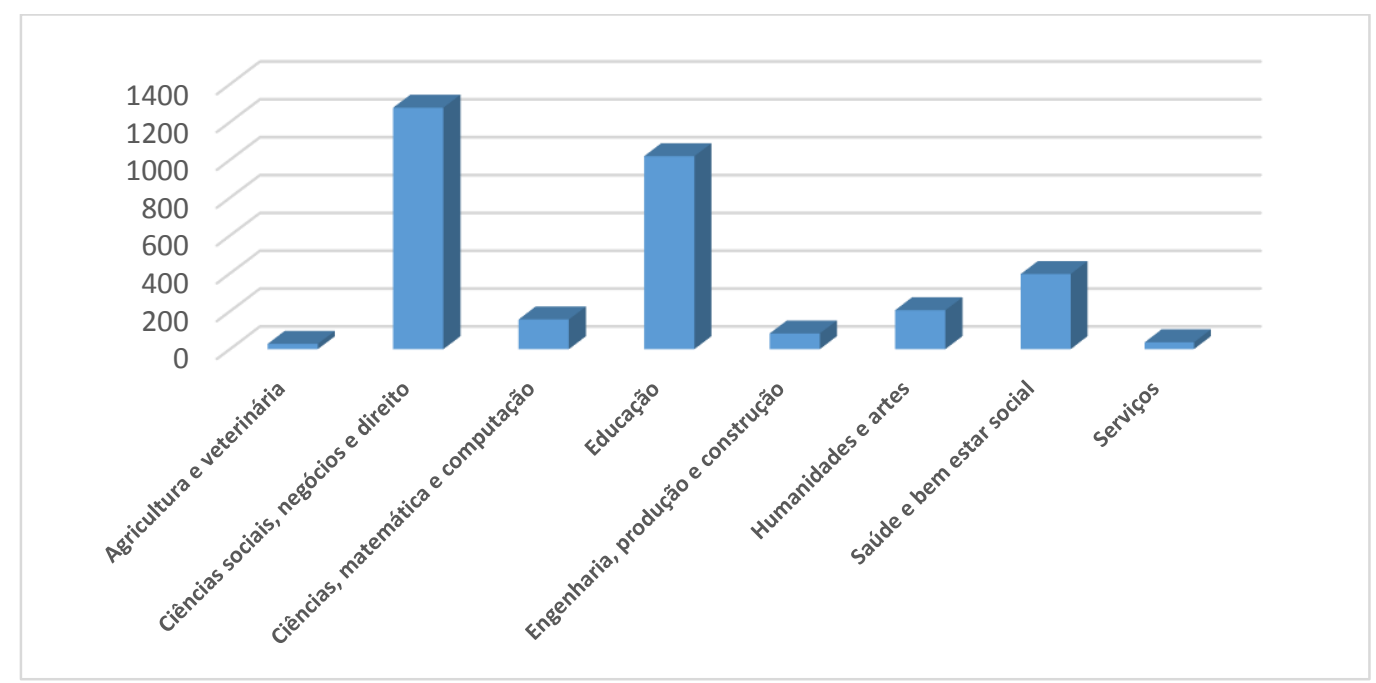

Fonte: Ministério da Educação - Sistema e-MEC

Relatório Processado: 20/04/2015

Essa concentração de áreas, deve-se a demandas de mercado, com mais formados em cursos superiores de Administração, Direito e Pedagogia. Também pesam as dificuldades em abrir cursos em outros setores, como Saúde e Engenharia, que enfrentam resistência das entidades de classe.

A metodologia empregada, na Pós-graduação em EaD, é a que estimula a conexão entre as informações, o que proporciona a construção do conhecimento, por meio de multiplicidade de recursos pedagógicos que puderam ser desenvolvidos após o grande avanço tecnológico dos últimos tempos. A educação a distância pressupõe que, na maior parte do tempo, professores e alunos não estejam no mesmo espaço-temporal, o que não significa ausência, mas a mediatização da relação professor/aluno por mecanismos da informação.

Tabela 3: Carga horária dos Cursos de Pós-graduação ativos e desativados.

\begin{tabular}{lllll}
\hline \multirow{2}{*}{ Carga Horária } & Ativo & \multicolumn{2}{c}{ Desativado } \\
\cline { 2 - 5 } & $\boldsymbol{f}$ & $\%$ & $\boldsymbol{f}$ & $\%$ \\
\hline 360 horas & 866 & $27,0 \%$ & 12 & $13,3 \%$ \\
361 a 500 horas & 2101 & $65,6 \%$ & 67 & $74,4 \%$ \\
501 a 750 horas & 220 & $6,9 \%$ & 10 & $11,1 \%$ \\
751 a 1000 horas & 9 & $0,3 \%$ & 0 & $0,0 \%$ \\
Acima de 1000 horas & 7 & $0,2 \%$ & 1 & $1,1 \%$ \\
\hline Total & $\mathbf{3 2 0 3}$ & $\mathbf{1 0 0 , 0} \%$ & $\mathbf{9 0}$ & $\mathbf{1 0 0 , 0} \%$ \\
\hline
\end{tabular}

Fonte: Ministério da Educação - Sistema e-MEC

Relatório Processado: 20/04/2015 
A Tabela 3, de acordo com a Resolução CNE/CES № 1, os cursos de Pósgraduação têm duração mínima de 360 horas, são 866 (27,0\%) cursos; com 361 a 500 horas são $2101(65,6 \%)$ cursos.

A RESOLUÇÃO CNE/CES №1, DE 3 DE ABRIL DE 2001.

Art. 6을 Os cursos de pós-graduação lato sensu oferecidos por instituições de ensino superior ou por instituições especialmente credenciadas para atuarem nesse nível educacional independem de autorização, reconhecimento e renovação de reconhecimento e devem atender ao disposto nesta Resolução.

Art. 10 Os cursos de pós-graduação lato sensu têm duração mínima de 360 (trezentos e sessenta) horas, nestas não computado o tempo de estudo individual ou em grupo, sem assistência docente, e o reservado, obrigatoriamente, para elaboração de monografia ou trabalho de conclusão de curso.

Art. 11 Os cursos de pós-graduação lato sensu a distância só poderão ser oferecidos por instituições credenciadas pela União, conforme o disposto no $\S 1^{\circ}$ do art. 80 da Lei 9.394, de 1996. Parágrafo único. Os cursos de pós-graduação lato sensu oferecidos a distância deverão incluir, necessariamente, provas presenciais e defesa presencial de monografia ou trabalho de conclusão de curso.

\section{Referências}

ALONSO, Katia Morosov. Tecnologias da informação e comunicação e formação de professores: sobre rede e escolas. 2008. Disponível em:

$<$ http://www.scielo.br/scielo.php?script=sci issues\&pid=01017330\&lng=pt\&nrm=iso $>$, Acesso em: 15 março. 2015.

BRASIL. Ministério da Educação - E-MEC, Instituições de Educação Superior e Cursos Cadastrados. Disponível em: http://emec.mec.gov.br/, Acesso em 20 abril 2015.

DOURADO, L.F; SANTOS, C.A. A Educação a Distância no contexto atual e o PNE 2011-2020: avaliação e perspectivas. Goiânia: editora: UFG; Belo Horizonte: Editora autêntica, 2012.

SANTOS, Catarina de Almeida. A expansão da educação superior rumo à expansão do capital: interfaces com a educação a distância no Brasil, 2008. Tese (Doutorado) - Faculdade de Educação da Universidade de São Paulo (USP). São Paulo. Disponível em: http://www.teses.usp.br/teses/disponiveis/48/48134/tde25092009-163728/pt-br.php. Acesso em novembro de 2010. 
PIMENTA, Selma Garrido; ANASTASIOU, Lea das Graças Camargos. Docência no ensino superior. Volume I. São Paulo: Cortez, 2002. p. 100-101. 